\title{
Fire Resistance Performance of FRP Rebar Reinforced Concrete Columns
}

\author{
Hui Wang, ${ }^{1)}$ Xiaoxiong $\mathrm{Zha}^{1{ }^{1}}$ and Jianqiao $\mathrm{Ye}^{2)}$ \\ (Received June 26, 2009, Revised November 29, 2009, Accepted November 30, 2009)
}

\begin{abstract}
Concrete columns reinforced with Fibre Reinforced Polymer (FRP) rebar have been increasingly used in civil engineering applications, while the research on fire resistance of such structural members is still very limited. In this paper, attempts are made to predict temperature distribution and mechanical performance of FRP rebar reinforced concrete columns in fire. The effect of concrete cover and section size on fire resistance time is studied by the finite element method. Based on a parametric study, a simple empirical formula to predict fire resistance time is proposed for possible adoption in fire resistance design.
\end{abstract}

Keywords : fire resistance, fibre reinforced polymer, concrete columns, finite element method, empirical formula

\section{Introduction}

Compared with steel, Fibre Reinforced Polymer (FRP) has the advantages of low mass to volume ratio, high strength, corrosion resistance, fatigue resistance and electromagnetic interference resistance. ${ }^{16}$ The use of FRP rebar in concrete as an alternative to the traditional steel ones can effectively solve the rust induced durability problems, resulting in an enhanced structure service life, and hence has wide applications in civil engineering structures. However, due to the unfavorable thermal properties of FRP materials, fire resistance of FRP reinforced member is inevitably reduced. Some preliminary studies revealed the fact that the behaviour of FRP rebar reinforced concrete under fire exposure is quite different from conventional steel reinforced concrete. When embedded in concrete, the lack of oxygen will inhibit the burning of FRP reinforcement, but the resin will soften. The critical time will occur when the resin on the surface of the FRP bar reaches its glass transition temperature. At this point, the resin will no longer be able to transfer stresses from the concrete to the fibre, i.e. the bond will fail. Locally this may result in increased crack width hence increased deformation. There is therefore an urgent need to carry out extensive research, so that fire resistance performance of FRP reinforced members can be better understood and FRP materials can be used in civil engineering applications more efficiently and more effectively.

Experimental and theoretical studies on the strength, bond-slip, crack and durability of FRP rebar reinforced concrete have been

\footnotetext{
${ }^{1)}$ Shenzhen Graduate School, Harbin Institute of Technology, Shenzhen 518055, China.

${ }^{2)}$ Institute of Resilient Infrastructure (iRI), School of Civil Engineering, the University of Leeds, Leeds, LS2 9JT, UK. Email: J.Ye@leeds.ac.uk.

Copyright (c) 2009, Korea Concrete Institute. All rights reserved, including the making of copies without the written permission of the copyright proprietors.
}

carried out worldwide for a few decades. ${ }^{2,6,11}$ In 1993 the world's first concrete structural design guidelines on using FRP materials were produced in Japan. However, the research on fire resistance of FRP reinforced concrete has merely started rather recently., ${ }^{2,4}$ The investigations on this field are extremely essential, not only in terms of fundamental understanding of structural behavior under fire conditions, but also contributing to the fire resistance standard and guiding practical designs. In this paper, the finite element method is used to simulate thermal and mechanical behavior of FRP reinforced concrete columns. Parametric studies are carried out to evaluate the influence of concrete cover thickness and section size on the fire resistance performance of FRP rebar reinforced concrete columns. On the basis of the results, an approximate formula is proposed to predict fire resistance time in terms of cover thickness and section size.

\section{Finite element modeling}

\subsection{The constitutive law of materials}

To increase the strength and stiffness of a concrete column, steel rebar are normally used as reinforcement in the axial direction. This reinforcement can now be replaced by pre-fabricated FRP rebar. The concrete of a column is normally subjected to compression and exhibits a nonlinear strain-stress relationship as shown in Fig. 1.

Under a fire condition, the material properties of the concrete shown in Figure 1 are taken as temperature dependent and the temperature dependent properties are presented in Table 1. 9,14

FRP rebar is normally assumed as a linear elastic material, without a significant yield stage. The constitutive law of FRP is shown in Fig. 2. In this paper, glass fibre reinforced polymer (GFRP) is used as the reinforcement in the finite element analysis.

Under a fire condition, the strength and the elastic modulus of GFRP change with temperature. The reduced ultimate strength and elastic modulus of the FRP rebar due to elevated temperature 


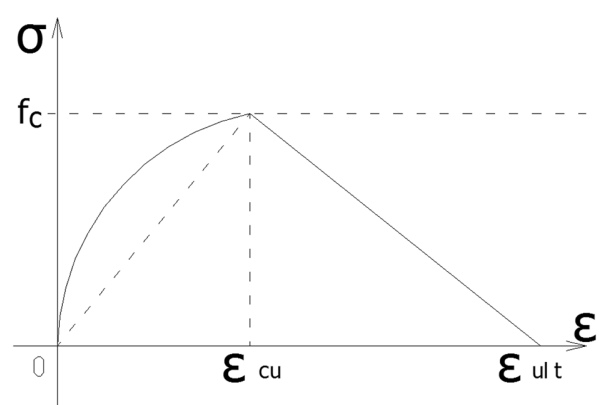

Fig. 1 The constitutive law of concrete.

Table 1 Material properties of concrete viz temperature variation.

\begin{tabular}{c|c|c|c}
\hline Temperature $\left({ }^{\circ} \mathrm{C}\right)$ & $k_{C}=f_{C, T} / f_{C}$ & $\varepsilon_{c u, T} \times 10^{3}$ & $\varepsilon_{u l t, T} \times 10^{3}$ \\
\hline \hline 20 & 1.0 & 2.5 & 20.0 \\
\hline 100 & 0.95 & 3.5 & 22.5 \\
\hline 200 & 0.90 & 4.5 & 25.0 \\
\hline 300 & 0.85 & 6.0 & 27.5 \\
\hline 400 & 0.75 & 7.5 & 30.0 \\
\hline 500 & 0.60 & 9.5 & 32.5 \\
\hline 600 & 0.45 & 12.5 & 35.0 \\
\hline 700 & 0.30 & 14.0 & 37.5 \\
\hline 800 & 0.15 & 14.5 & 40.0 \\
\hline 900 & 0.08 & 15.0 & 42.5 \\
\hline 1,000 & 0.04 & 15.0 & 45.0 \\
\hline 1,100 & 0.01 & 15.0 & 47.5 \\
\hline 1,200 & 0.0 & 15.0 & 50.0 \\
\hline
\end{tabular}

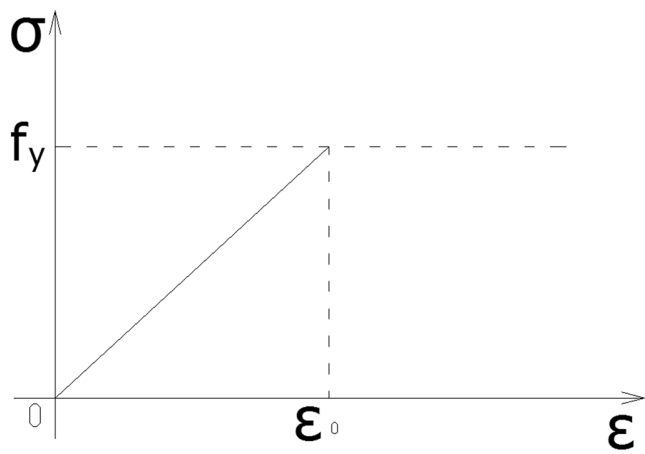

Fig. 2 The constitutive law of FRP.

can be obtained from the following equations ${ }^{13)}$

$$
\begin{aligned}
& \frac{f_{\text {fu } T}}{f_{\text {fu } 20}}=k_{f} \\
& \frac{E_{\mathrm{f} T}}{E_{\mathrm{f} 20}}=k_{E}
\end{aligned}
$$

where $\mathrm{f}_{\text {fu2 } 20}$ and $\mathrm{f}_{\text {fuT }}$ are the ultimate tensile strength of GFRP rebar at $20^{\circ}$ and an elevated temperature $\mathrm{T}$, respectively; $\mathrm{E}_{\mathrm{f} 20}$ and $\mathrm{E}_{\mathrm{fT}}$ are the respective elastic modulus; $\mathrm{k}_{\mathrm{f}}$ and $\mathrm{k}_{\mathrm{E}}$ are temperature reduction factors of tensile strength and elastic modulus. The reduction factors, $\mathrm{k}_{\mathrm{f}}$ and $\mathrm{k}_{\mathrm{E}}$, as a function of temperature are calculated as follows.

$$
\begin{array}{ll}
k_{f}=1-0.0025 T & 0 \leq T \leq 400 \\
k_{f}=0 & 400 \leq T \\
k_{E}=1 & 0 \leq T \leq 100 \\
k_{E}=1.25-0.0025 T & 100 \leq T \leq 300 \\
k_{E}=2-0.005 T & 300 \leq T \leq 400 \\
k_{E}=0 & 400 \leq T
\end{array}
$$

\subsection{Thermal properties of materials}

The thermal conductivity, specific heat capacity and thermal expansion coefficient of concrete are taken as follows. ${ }^{12}$

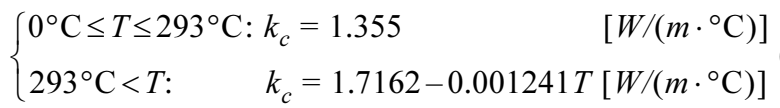

where $\mathrm{k}_{\mathrm{c}}$ is thermal conductivity of concrete and $\mathrm{T}$ is the time dependent temperature of concrete.

The specific heat capacity $C_{c}$ and the density of concrete $\rho_{c}$ satisfy the following equations :

$$
\begin{aligned}
& 0^{\circ} \mathrm{C} \leq T \leq 400^{\circ} \mathrm{C}: \rho_{c} \mathrm{c}_{c}=2.566 \times 10^{6} \\
& {\left[J /\left(m^{3} \cdot{ }^{\circ} \mathrm{C}\right)\right]} \\
& 400^{\circ} \mathrm{C}<T \leq 410^{\circ} \mathrm{C}: \rho_{c} \mathrm{c}_{c}=(0.1765 T-68.034) \times 10^{6} \\
& {\left[\mathrm{~J} /\left(\mathrm{m}^{3} \cdot{ }^{\circ} \mathrm{C}\right)\right]} \\
& 410^{\circ} \mathrm{C}<T \leq 445^{\circ} \mathrm{C}: \rho_{c} \mathrm{c}_{c}=(-0.05043 T+25.00671) \times 10^{6} \\
& {\left[\mathrm{~J} /\left(\mathrm{m}^{3} \cdot{ }^{\circ} \mathrm{C}\right)\right]} \\
& 445^{\circ} \mathrm{C}<T \leq 500^{\circ} \mathrm{C}: \rho_{c} \mathrm{c}_{c}=2.566 \times 10^{6} \\
& {\left[\mathrm{~J} /\left(\mathrm{m}^{3} \cdot{ }^{\circ} \mathrm{C}\right)\right]} \\
& 500^{\circ} \mathrm{C}<T \leq 635^{\circ} \mathrm{C}: \rho_{c} \mathrm{c}_{c}=(0.01603 T-5.44881) \times 10^{6} \\
& {\left[\mathrm{~J} /\left(\mathrm{m}^{3} \cdot{ }^{\circ} \mathrm{C}\right)\right]} \\
& 635^{\circ} \mathrm{C}<T \leq 715^{\circ} \mathrm{C}: \rho_{c} \mathrm{c}_{c}=(0.16635 T-100.90225) \times 10^{6} \\
& {\left[\mathrm{~J} /\left(\mathrm{m}^{3} \cdot{ }^{\circ} \mathrm{C}\right)\right]} \\
& 715^{\circ} \mathrm{C}<T \leq 785^{\circ} \mathrm{C}: \rho_{c} \mathrm{c}_{c}=(-0.22103 T+176.07343) \times 10^{6} \\
& {\left[\mathrm{~J} /\left(\mathrm{m}^{3} \cdot{ }^{\circ} \mathrm{C}\right)\right]} \\
& 785^{\circ} \mathrm{C}<T: \quad \rho_{c} \mathrm{c}_{c}=2.566 \times 10^{6} \\
& {\left[\mathrm{~J} /\left(\mathrm{m}^{3} \cdot{ }^{\circ} \mathrm{C}\right)\right]}
\end{aligned}
$$

where $\rho_{\mathrm{c}}$ is taken as $2,350 \mathrm{~kg} / \mathrm{m}^{3}$ in this paper. The thermal expansion coefficient of concrete is calculated by

$$
\alpha_{c}=(0.008 T+6) \times 10^{-6}\left[\mathrm{~m} /\left(\mathrm{m} \cdot{ }^{\circ} \mathrm{C}\right)\right]
$$

The thermal expansion coefficient of the FRP rebar is taken as $3.3 \times 10^{-5} \mathrm{~m} /\left(\mathrm{m} \cdot{ }^{\circ} \mathrm{C}\right)$. It is found that the information about ther- 
mal conductivity, specific heat capacity of FRP rebar is very limited. Becker, et $\mathrm{al}^{3}$ suggested that if the area of rebar in concrete is less than 4 percent of the total area of the reinforced cross section, the temperature of the rebar in concrete is approximately equal to the temperature at the same locations by assuming that the section is of plain concrete. In the following calculations, this approximation is adopted.

\subsection{Finite element model}

This paper uses the finite element analysis software ABAQUS to simulate the performance of FRP rebar reinforced concrete columns subjected to externally applied axial load and elevated temperature. The following assumptions are made in the calculations:

1) No relative slip exists between FRP rebar and concrete. The displacements of FRP rebar and concrete are continuous across the interface.

2) Creep is not considered. Since creep is not a dominating factor in fire resistance analysis, it is ignored in the following study without introducing significant errors.

3) Due to the fact that the deformation of the column is very small, the influence of the strain on the temperature distribution is ignored. However, the influence of the strain on temperature must be considered when the deformation has great influence on heat flux $^{5}$

4) The thermal contact at the interface between concrete and FRP is 'perfect', and a continuous temperature field across the interface is considered.

Fig. 3 shows the finite element model of a FRP rebar reinforced concrete column. Both ends are fixed, and only axial displacement at the top of the column is permitted. Eight-node solid elements are used for both thermal and mechanical analyses. A concentrated load is applied through an imaginary rigid plate attached to the top end, by which a uniform end displacement is achieved. The analysis of fire resistance of the FRP rebar reinforced concrete column is a complicated process, involving the analysis of temperature distribution, heat transfer and structural responses that are all time dependent. The material properties, such as thermal conductivity, specific heat capacity, thermal expansion coefficient, variations of

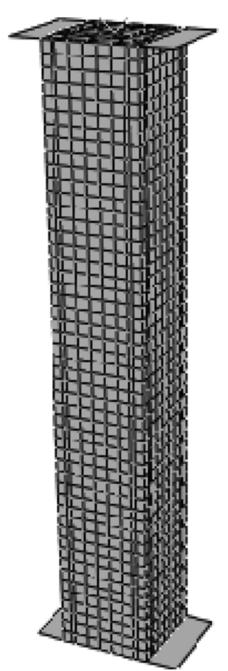

Fig. 3 Finite element model of FRP rebar reinforced concrete column. the mechanical properties with temperature have to be taken into account in the calculation. At each time instance, the temperature distribution is calculated first by the heat transfer analysis. The temperature at all the nodes of the finite element meshes are recorded and then is taken as nodal temperature in the mechanical analysis.

\subsection{Model of fire temperature}

It is assumed that heat is transferred to the surface of the column from fire by convection and radiation in the calculation. The heat transferred satisfies the following equation:

$$
q=h\left(T_{f}-T_{s}\right)+\varepsilon \sigma\left(\theta_{f}^{4}-\theta_{s}^{4}\right)
$$

where, $\mathrm{h}$ is the heat transfer coefficient for convection, taken as $25 \mathrm{~W} / \mathrm{m}^{2}$; $\varepsilon$ is emissivity, taken as 0.7 ; and $\sigma$ is the Boltzmann constant, taken as $5.67 \times 10^{-8} \mathrm{~W} / \mathrm{m}^{2} \mathrm{~T}^{4}$. $\mathrm{T}_{\mathrm{f}}$ is the Celsius temperature of fire and Ts the surface temperature of column; $\theta_{\mathrm{f}}$ is the absolute temperature of fire and $\theta_{\mathrm{s}}$ the absolute surface temperature of the column.

\section{Test verification}

In order to verify the finite element analysis of temperature distribution within FRP reinforced concrete columns, the computed distributions are compared with the test results from Sakashita, et

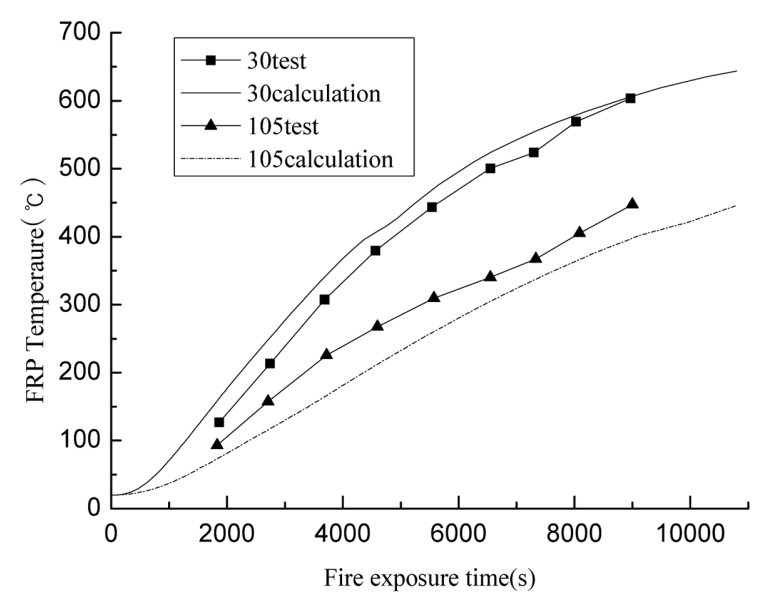

Fig. 4 Verification of the temperature field.

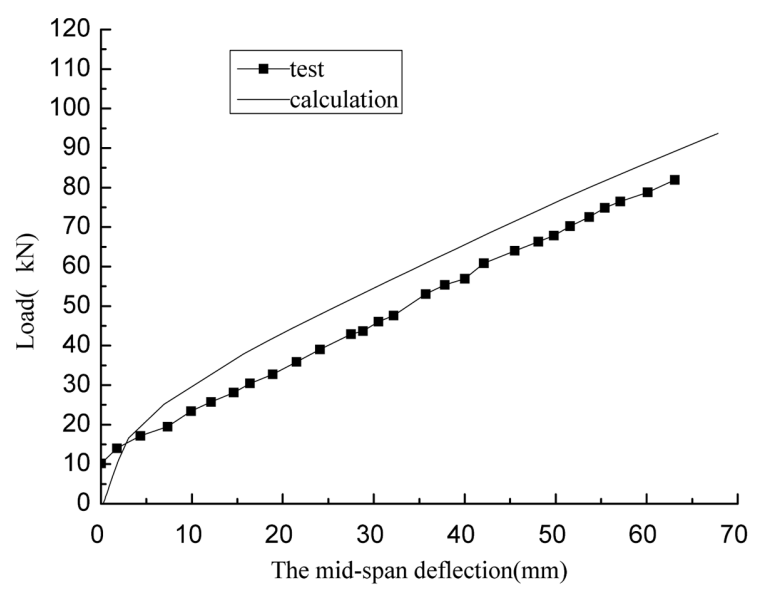

Fig. 5 Verification of the mechanical properties in fire. 
$\mathrm{al}^{14}$ for two columns that are $4 \mathrm{~m}$ long with a cross-sectional area of $400 \times 350 \mathrm{~mm}^{2}$. The columns were reinforced symmetrically by two FRP bars. The concrete cover thicknesses of the two members are $30 \mathrm{~mm}$ and $105 \mathrm{~mm}$, respectively. The external temperature $\mathrm{T}$ is assumed to follow the standard temperature curve specified by ISO-834. Fig. 4 compares the temperature-time curves of the FRP rebar from the FEM calculation with those from the tests. It can be seen that the temperature field from the FE calculation agrees reasonably well with the experimental results for both cases.

To validate the FEM analysis of deformation for a FRP reinforced concrete member subjected to both mechanical and temperature loads, the calculated results are compared with the test results from Elzaroug, et al. ${ }^{7}$ Fig. 5 presents the comparisons for mid-span deflection of a concrete beam reinforced with FRP rebar. Again, the computed results agree well with the experimental data. The above validations show that the established finite element model can stimulate both thermal and mechanical behavior of FRP reinforced members satisfactorily.

\section{Results and discussion}

After successful comparison, the finite element model is applied further to investigate fire resistance performance of FRP rebar reinforced columns. All the reinforced concrete columns are $2 \mathrm{~m}$ long and of square cross-sections. Four $15 \times 15 \mathrm{~mm}$ square FRP rebar are symmetrically placed with a variable cover thickness $\mathrm{c}$. Figure 6 shows the reinforced section.

\subsection{Analysis of fire temperature field}

The external temperature $\mathrm{T}$ is assumed to follow the standard temperature curve ISO-834. All the FRP rebar reinforced concrete columns are considered to be exposed to all-around fire. The computed temperature distribution over a typical cross-section is presented in Fig. 7. Figure 8 shows the temperature distribution along the axis of symmetry of the section at six different time instances. It is noted that the temperature of the materials near the column surface increases much faster than those near the centre of the column during the fire exposure.

Figures 9 and 10, respectively, show the temperature history of the FRP rebar for different concrete cover thickness and section sizes. As expected, the results given in the two figures demonstrate that for a given section the thicker the concrete cover is, the

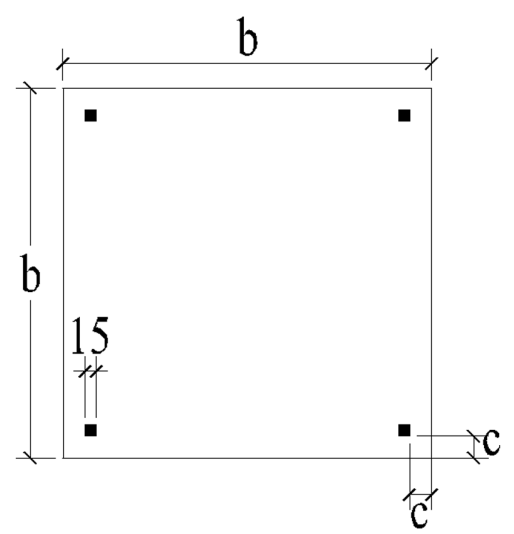

Fig. 6 The cross section of FRP rebar reinforced concrete column.

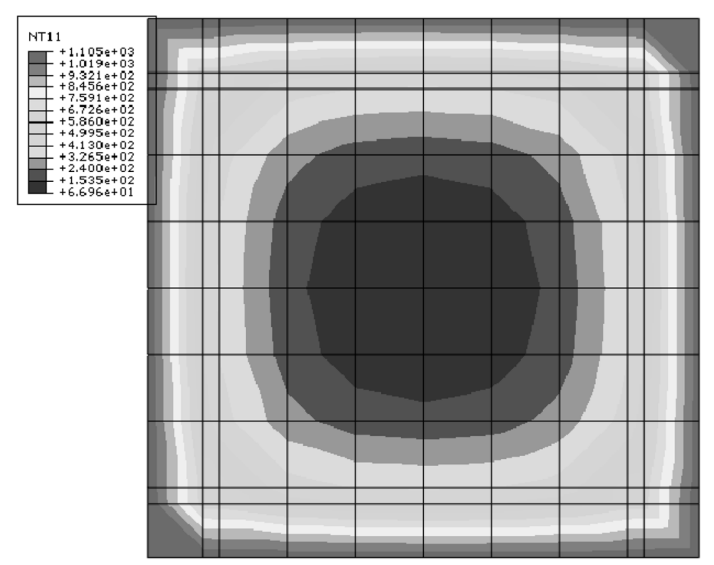

Fig. 7 Temperature distribution on the cross-section of the FRP reinforced concrete column at $180 \mathrm{~min}$ (side length $b=500 \mathrm{~mm}$, concrete cover $c=50 \mathrm{~mm}$ ).

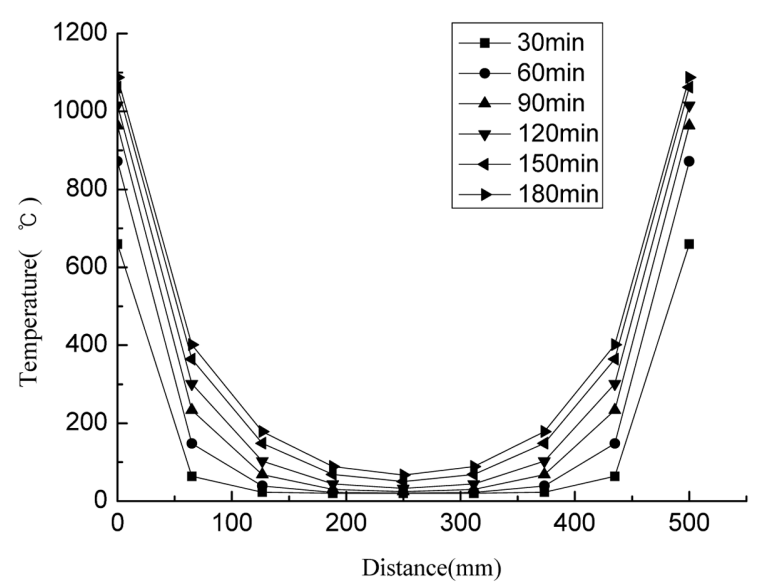

Fig. 8 Temperature distribution profiles along the axis of symmetry at various times (side length $b=500 \mathrm{~mm}$, concrete cover $c=50 \mathrm{~mm}$ ).

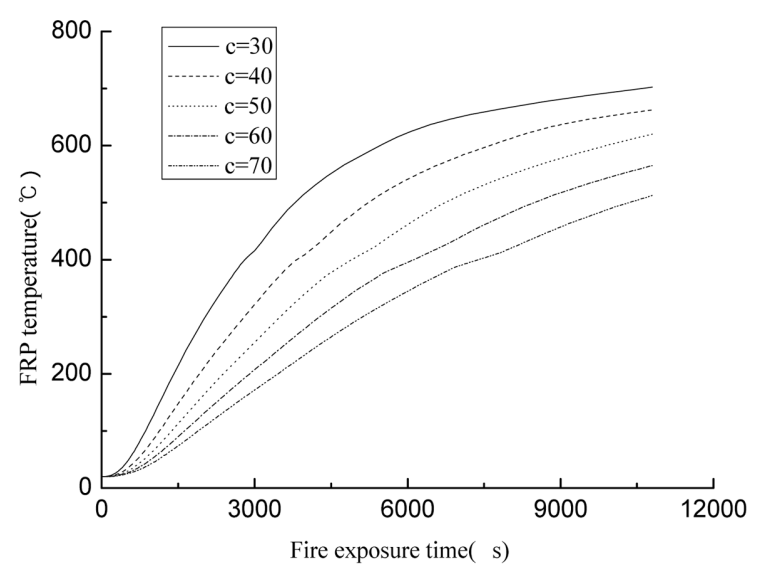

Fig. 9 Temperature-time curve of the FRP rebar for various cover thickness $(b=500 \mathrm{~mm})$.

lower the temperature of FRP rebar will be. It is noticed that the temperature-time curves alter only marginally when the size of the section changes. Obviously, the influence of concrete cover on the temperature of FRP rebar is much greater than that of the overall size of section. 


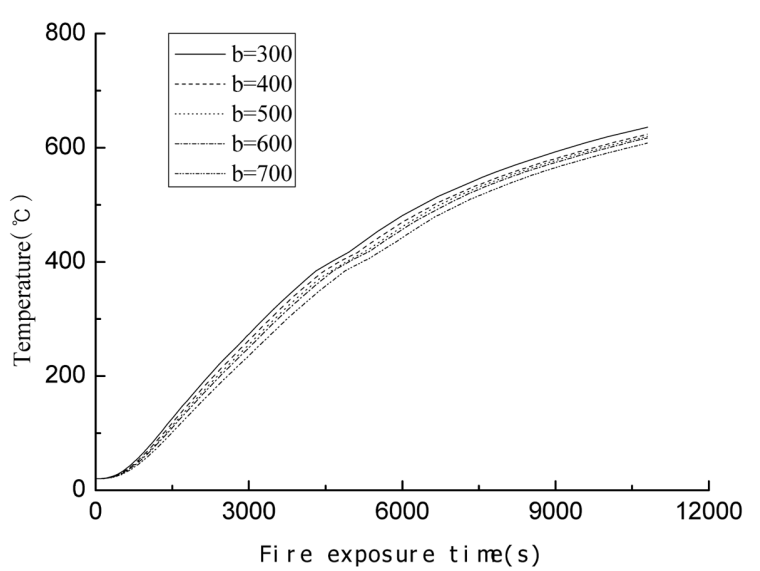

Fig. 10 Temperature-time curve of the FRP rebar for various section sizes $(c=50 \mathrm{~mm})$.

\subsection{Top end displacement of the column in fire}

To compute deformation of the columns under fire, axis loads applied on the top end are assumed to be about 50 percent of the ultimate bearing capacity of the columns at normal temperature $\left(20^{\circ} \mathrm{C}\right)$. The columns are completely fixed at the bottom ends and partially fixed at the top ends to allow vertical displacement. The reinforcements are located as shown in Fig. 6 with a variable thicknesss of concrete cover, i.e., $30,40,50,60$ and $70 \mathrm{~mm}$, respectively. The tensile strength of the FRP and the cube compressive strength of the concrete are taken as $640 \mathrm{MPa}$ and $30 \mathrm{MPa}$, respectively. According to the sizes of the cross-section, the loads applied on the top ends of the columns are presented in Table 2.

Figures 11 and 12 respectively present the vertical displacements of the top ends in terms of fire exposure time for different concrete covers and section sizes. Fig. 11 shows that the largest end displacement occurs when $\mathrm{c}=30 \mathrm{~mm}$. The displacement decreases as the thickness of concrete cover increases since the cover delays the temperature induced stiffness degradation of the FRP rebar. Fig. 12 shows that the top end displacement is in general decreasing as the size of the cross section increases. This can be explained as that when a column has a larger cross section, it

Table 2 Axial loads applied on the top of column.

\begin{tabular}{c|c|c|c|c|c}
\hline Side length $(\mathrm{mm})$ & 300 & 400 & 500 & 600 & 700 \\
\hline \hline Load on the top of column $(\mathrm{kN})$ & 838 & 1,289 & 1,868 & 2,576 & 3,412 \\
\hline
\end{tabular}

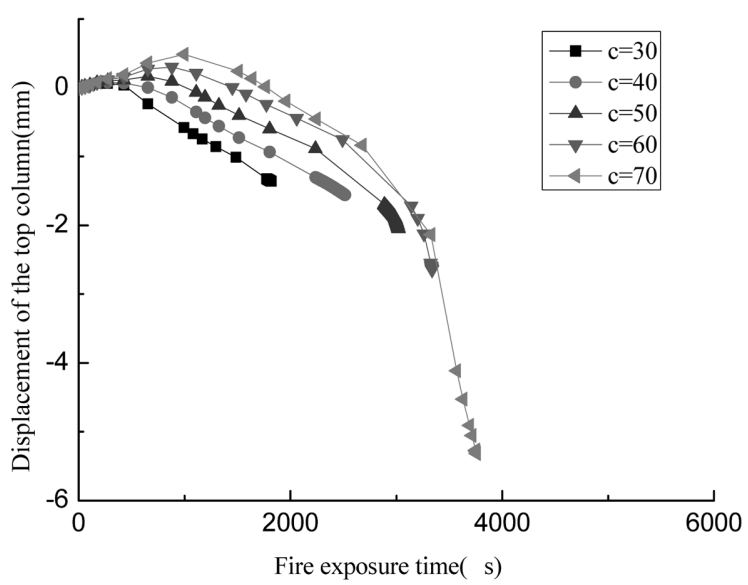

Fig. 11 Displacement-time curve of the top end for various concrete cover thickness $(b=700 \mathrm{~mm})$.

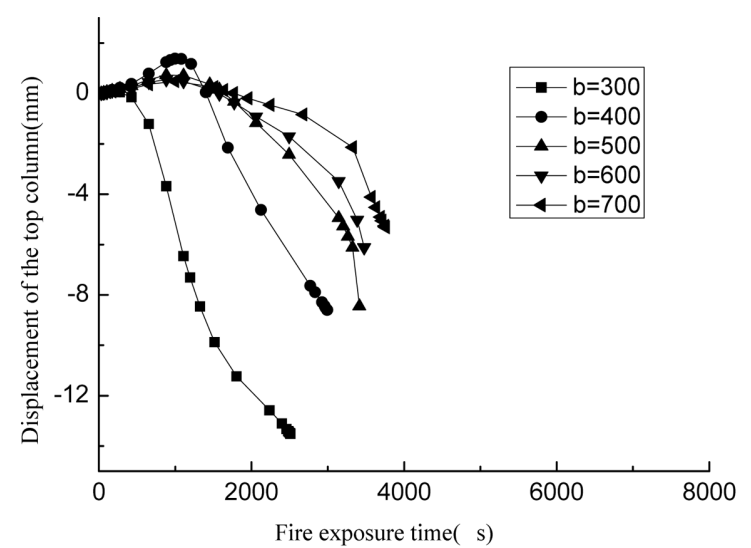

Fig. 12 Displacement-time curve of the top end for various section sizes $(c=70 \mathrm{~mm})$.

has a larger 'centre' area with much lower temperature. Consequently, this will reduce the temperature related strength and stiffness degradation of the concrete significantly and therefore the overall section will have a higher average strength and stiffness.

\subsection{The effect of concrete cover thickness on fire resistance time}

The fire resistance time is mainly determined by computing the time when an abrupt increase of the end displacement occurs. Fire resistance time variations with the thickness of concrete cover for different sizes of section are presented in Fig. 13. It is noted that for a given section the thicker the concrete cover is, the longer the fire resistance time will be. Any increase of concrete cover thickness delays temperature increase within the columns and, thus, the strength and stiffness degradation of the FRP rebar. As a result, it improves fire resistance performance of the columns.

\subsection{The effect of section size on fire resistance time}

Fig. 14 presents the fire resistance time for columns with various section sizes and thickness of concrete cover. In general, the fire resistance time is proportional to the size of section. This is because FRP rebar have lower thermal stability and fire resistance than concrete. An increase of section size will reduce its reinforcement ratio and improves the overall all fire resistance performance. Also, it is understandable that the larger the section size is,

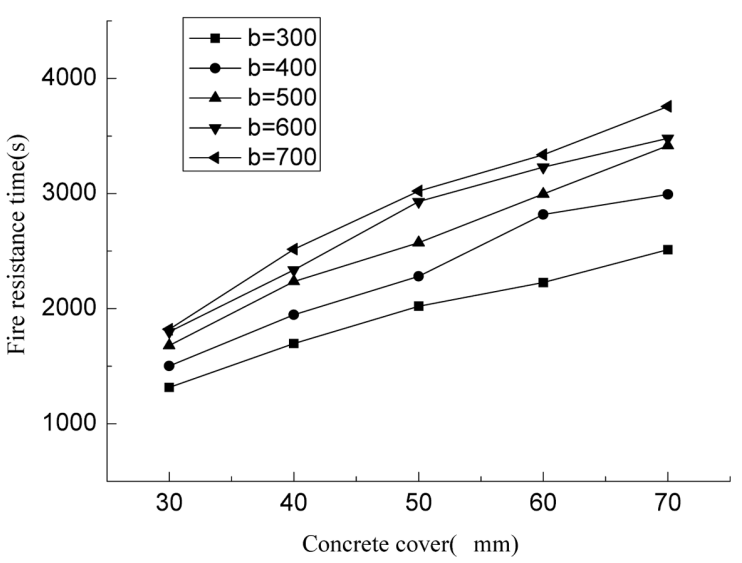

Fig. 13 Fire resistance time viz concrete cover thickness for various section sizes. 


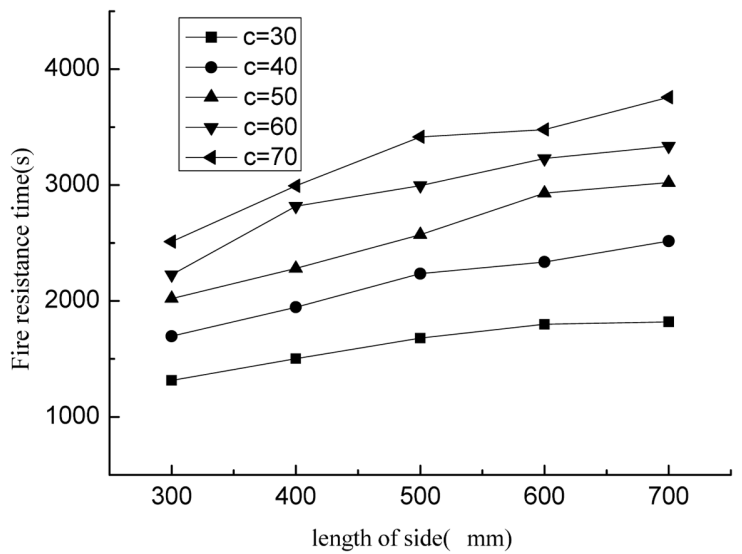

Fig. 14 Fire resistance time viz section size for various concrete cover thickness.

the lower the average temperature of the section will be, and, therefore, the slower the deterioration of the materials will be. However, compared with concrete cover, the size of section plays a less important role in improving fire resistance.

\subsection{Fire resistance time formula}

On the basis of the numerical calculations, an empirical formula is established from extensive parametric studies, including the results presented in the previous section. The constants used in the formula are obtained through statistic correlation between the simple solution and the finite element results. The formula calculates fire resistance time of FRP rebar reinforced columns by taking into account the influence of concrete cover thickness and section size. The formula is shown below.

$$
f(c, b)=0.38478 c^{2}-0.00147 b^{2}+3.71374 b \quad 0 \leq c \leq b \leq 2526
$$

where $c$ is concrete cover thickness; $b$ denotes side length of a square section; $\mathrm{f}(\mathrm{c}, \mathrm{b})$ represents fire resistance time that is a function of $c$ and $b$. Table 3 shows application of the formula and compares the computed fire resistance time from Eq. (9) with the FEM results. It can be seen from the table that the differences between the two solutions are within 10 percent for most of the cases. The larger discrepancies occur for columns having either a large section size with a small cover thickness or a large cover thickness with a small section size. The reasonably good agreement suggests that the proposed formula may be further calibrated and verified for possible adoption in practical design. It is worth mentioning that for a positive fire resistance time, $0 \leq c \leq b \leq 2526$ must be satisfied in Eq. (9).

\section{Conclusions}

This paper studied the performance of FRP rebar reinforced concrete columns under fire condition by the finite element method. The temperature dependent strength and stiffness properties of both concrete and FRP reinforcement were considered in the calculation. The finite element model was verified by comparing it solution with available test results.

The numerical investigation demonstrated that for a small rein-
Table 3 Fire resistance time from both the empirical and numerical solutions.

\begin{tabular}{|c|c|c|c|c|}
\hline $\begin{array}{c}\text { Concrete } \\
\text { cover }(\mathrm{mm})\end{array}$ & $\begin{array}{l}\text { Side length } \\
(\mathrm{mm})\end{array}$ & $\begin{array}{l}\text { Finite element } \\
\text { results (s) }\end{array}$ & $\begin{array}{c}\text { Formula } \\
\text { results (s) }\end{array}$ & $\begin{array}{c}\text { Error } \\
(\%)\end{array}$ \\
\hline \multirow{5}{*}{30} & 300 & 1315 & 101328.124 & 0.998 \\
\hline & 400 & 1503 & 1596.598 & 6.227 \\
\hline & 500 & 1680 & 1835.672 & 9.266 \\
\hline & 600 & 1800 & 2045.346 & 13.630 \\
\hline & 700 & 1819 & 2225.62 & 22.354 \\
\hline \multirow{5}{*}{40} & 300 & 1696 & 1597.47 & -5.810 \\
\hline & 400 & 1946 & 1865.944 & -4.114 \\
\hline & 500 & 2236 & 2105.018 & -5.858 \\
\hline & 600 & 2337 & 2314.692 & -0.955 \\
\hline & 700 & 2516 & 2494.966 & -0.836 \\
\hline \multirow{5}{*}{50} & 300 & 2020 & 1943.772 & -3.774 \\
\hline & 400 & 2280 & 2212.246 & -2.972 \\
\hline & 500 & 2573 & 2451.32 & -4.729 \\
\hline & 600 & 2929 & 2660.994 & -9.150 \\
\hline & 700 & 3020 & 2841.268 & -5.918 \\
\hline \multirow{5}{*}{60} & 300 & 2226 & 2367.03 & 6.336 \\
\hline & 400 & 2817 & 2635.504 & -6.443 \\
\hline & 500 & 2995 & 2874.578 & -4.021 \\
\hline & 600 & 3230 & 3084.252 & -4.512 \\
\hline & 700 & 3337 & 3264.526 & -2.172 \\
\hline \multirow{5}{*}{70} & 300 & 2511 & 2867.244 & 14.187 \\
\hline & 400 & 2992 & 3135.718 & 4.803 \\
\hline & 500 & 3415 & 3374.792 & -1.177 \\
\hline & 600 & 3478 & 3584.466 & 3.061 \\
\hline & 700 & 3757 & 3764.74 & 0.206 \\
\hline
\end{tabular}

forcement ratio, FRP rebar in concrete had limited influence on the temperature distribution within the columns. The research also showed that fire resistance of the reinforced columns could be enhanced by increasing either the thickness of concrete cover or the cross-section size. It was noticed from the parametric studies that the thickness of concrete cover had greater influence on fire resistance than section size.

Based on the finite element analysis and extensive parametric studies, a simple empirical formula was proposed to compute fire resistance time of FRP rebar reinforced concrete columns in terms of concrete cover and size of section. Comparisons were made between the empirical and finite element solutions and the initial results suggested that it was possible to use the simple formula in practical design to predict fire resistance time, subject to future research and calibrations.

\section{Acknowledgements}

The second and third authors are grateful to the Royal Society for the financial support (2007/R1-IJP).

\section{References}

1. Abbasi, A. and Hogg, P. J., "Temperature and Environmental Effects on Glass Fibre Rebar: Modulus, Strength and Interfacial Bond Strength with Concrete," Composites: Part B. 36, 2005, pp. 394 404. 
2. Abbasi, A. and Hogg, P. J., "A Model for Predicting the Properties of the Constituents of a Glass Fibre Rebar Reinforced Concrete Beam at Elevated Temperatures Simulating a Fire Test," Composites: Part B, 36, 2005, pp. 384 393.

3. Becker, J., Bizri, H., and Bresler, B., FIRES-T: A Computer Program for the Fire Response of Structures-Thermal, California Univ., Berkeley National Science Foundation, Washington, DC UCB FRG-74-1, 1974, 76 pp.

4. Bisby, L. A. and Kodur, V., "Evaluating the Fire Endurance of Concrete Slabs Reinforced with FRP Bars: Considerations for a Holistic Approach," Composites: Part B, 38, 2007, pp. 547 558.

5. J. Duan, Z., Xiang, H., and Xue., M. D., "Thermal-dynamic Coupling Analysis of Large Space Structures Considering Geometric Nonlinearity," Int. J. Struct. Stab. Dy., Vol. 8, No. 4, 2008, pp. 569 596.

6. Elbadry, M. and Elzaroug, O., "Control of Cracking due to Temperature in Structural Concrete Reinforced with CFRP Bars," Composite Structures, Vol. 64, Issue 1, 2004, pp. 37 45.

7. Elzaroug, O., Forth, J. P., YE, J. Q., and Beeby, A. W., "Flexural Performance of Concrete Slabs Reinforced with GFRP and Subjected to Different Thermal Histories," Proceedings of FRPRCS-8, Greece, 2007.

8. Eurocode 4, "Design of Composite Steel and Concrete Structure-part1-2.1: General Rules-structural Fire Design,” European Committee for Standardization, Brussels, 1994.

9. Eurocode 2, "Design of Concrete Structures-Part1-2: General Rules-Structural Fire Design," European Committee for Standardization, Brussels.
10. Green, M. F., Bisby, L. A., Fam, A. Z., and Kodur, V., "FRP Confined Concrete Columns: Behaviour under Extreme Conditions," Cement \& Concrete Composites, Vol. 28, Issue 10, 2006, pp. 928 937.

11. Katz, A. and Berman, N., "Modeling the Effect of High Temperature on the Bond of FRP Reinforcing Bars to Concrete," Cement \& Concrete Composites, Vol. 22, No. 6, 2002, pp. 433 443.

12. Lie, T. T., Structural Fire Protection, New York: American Society of Civil Engineers, 1992.

13. Saafi, M., "Effect of Fire on FRP Reinforced Concrete Members," Composite Structures, Vol. 58, Issue 1, 2002, pp. 11 20.

14. Sakashita, M., Masuda, Y., Nakamura, K., Tanano, H., Nishida, I., and Hashimoto, T., "Deflections of Continuous Fibre Reinforced Concrete Beams under High Temperatures Loading," Non-metallic (FRP) Reinforcement Concrete Struct. Proc. 3rd Int Symp., 2, 1997, pp. 51 58.

15. Wang, Y. C. and Kodur, V., "Variation of Strength and Stiffness of Fibre Reinforced Polymer Reinforcing Bars with Temperature," Cement \& Concrete Composites, Vol. 27, Issue 9 10, 2005, pp. 864 874.

16. Wang, Y. C., Wong, P. M. H., and Kodur, V., “An Experimental Study of the Mechanical Properties of Fibre Reinforced Polymer (FRP) and Steel Reinforcing Bars at Elevated Temperatures," Composite Structures, Vol. 80, No. 1, 2007, pp. $131 \sim 140$. 